\title{
Two natural eudesmane-type sesquiterpenes from Laggera alata inhibit angiogenesis and suppress breast cancer cell migration through VEGF- and Angiopoietin 2-mediated signaling pathways
}

\author{
NING LIANG ${ }^{1}$, YAOLAN $\mathrm{LI}^{2}$ and HAU YIN CHUNG ${ }^{1}$ \\ ${ }^{1}$ Food and Nutritional Sciences Programme, School of Life Sciences, The Chinese University of Hong Kong, \\ Sha Tin, New Territories, Hong Kong, SAR; ${ }^{2}$ Institute of Traditional Chinese Medicine and Natural Products, \\ Guangdong Province Key Laboratory of Pharmacodynamic Constituents of TCM and \\ New Drugs Research, Jinan University, Guangzhou, Guangdong, P.R. China
}

Received August 15, 2016; Accepted February 28, 2017

DOI: 10.3892/ijo.2017.4004

\begin{abstract}
Eudesmane-type sesquiterpenes are natural sesquiterpenes with anti-inflammatory properties, but their anti-angiogenic activities are not known. The present study demonstrated that $5 \alpha$-hydroxycostic acid and hydroxyisocostic acid, two eudesmane-type sesquiterpenes (ETSs), isolated from the herb Laggera alata, possessed antiangiogenic effects. Under non-toxic dosage, ETSs suppressed VEGF-induced proliferation in human umbilical vein endothelial cells (HUVECs) and vessel formation in zebrafish embryos. Moreover, ETSs inhibited VEGF-stimulated HUVEC migration, stress fibers and tube formation. Results from real-time PCR analysis involving in vivo and in vitro experiments indicated that pro-angiogenic-related mRNA levels were downregulated, including VEGFA, VEGFR2 and Tie 2 genes after ETS treatments. Western blot analysis showed that ETSs suppressed VEGF-stimulated VEGFR2 phosphorylation and activation of its downstream molecules, such as Src/AKT/eNOS, FAK, PLC $\gamma /$ ERK1/2 and p38. Moreover, the VEGF-stimulation of angiopoietin 2 (Ang2) mRNA level increase was significantly downregulated in the presence of ETSs. ETSs inhibited Ang2-induced phosphorylation of the receptor Tie2 in HUVECs, which indicated that ETSs not just suppressed VEGF/VEGFR2 axis, but also the Ang2/ Tie2 one. Furthermore, the wound-healing assay revealed that ETSs reduced the migration of Ang2-stimulated human breast cancer (MCF-7) cells. Mechanistically, the anti-migration effect of ETSs correlated with the blockade of Ang2-induced E-cadherin loss and AKT activation. Collectively, the present
\end{abstract}

Correspondence to: Dr Hau Yin Chung, Food and Nutritional Sciences Programme, School of Life Sciences, The Chinese University of Hong Kong, Sha Tin, New Territories, Hong Kong, SAR, P.R. China E-mail: anthonychung@cuhk.edu.hk

Key words: eudesmane-type sesquiterpenes, anti-angiogenesis, VEGF, VEGFR2, angiopoietin 2, Tie2 study suggests that ETSs possess anti-angiogenic ability by interfering the VEGF- and Ang2-related pathways, and they may be good drug candidates.

\section{Introduction}

Angiogenesis refers to the process of new blood vessel formation, which constitutes a hallmark in physiological and pathological contexts, such as embryo development, wound healing, diabetic retinopathy and cancer metastasis $(1,2)$. Research on tumor angiogenesis progressed slowly until the discovery of the key molecular initiators of angiogenesis, i.e., the vascular endothelial growth factor (VEGF), and its endothelial cell specific tyrosine kinase receptor VEGFR (3). It is believed that the anti-angiogenic therapy could prevent cancer growth and metastasis.

VEGF has crucial and numerous effects on vascular endothelial cells. It acts as both pro-survival factor and stimulator of cell proliferation and migration, increases the vascular permeability, and initiates the development of new blood vessels (4). VEGF activates endothelial cells through VEGFR1 and VEGFR2, while VEGFR2 mediates the major angiogenic function of VEGF. VEGFR2 can lead to the activation of multiple downstream signal transduction cascades including the ERK1/2, the AKT and the focal adhesion kinase pathways (5). Besides, VEGF induces stress fiber formation to enhance vascular permeability and facilitates cell migration. Therefore, intervention in one or more of the pathways could downregulate the effect of VEGF signaling pathways. Development of the inhibitors for the VEGF/VEGFR2 signaling pathway has led to several approved FDA drugs which benefit hundreds of thousands of cancer patients. Bevacizumab (Avastin), a VEGF-targeted antibody, and sunitinib (Sutent), a VEGFR inhibitor, are some of the best-known drugs in this category (6).

However, clinical experiments also revealed cases of limited efficacy in the anti-VEGF therapy due to unknown causes (7). One proposed mechanism of the resistance involves tumors upregulating the alternate pro-angiogenic molecules, such as placental growth factor (PIGF), fibroblast growth 
factor 2 (FGF2) and angiopoietin 2 (Ang2). Due to the unique mode of function and increased understanding of both VEGFand Ang2-induced pathways, tremendous effort has been made to combine these two modalities to achieve enhanced outcomes (8).

As a ligand of the Tie2 receptor, Ang2 is exclusively expressed and stored in endothelial cells and functions as a partial Tie 2 agonist. It can be rapidly released following cytokine stimulation, such as $\operatorname{VEGF}(9,10)$. The Ang2/Tie2 system is an important angiogenic switch to promote vessel remodeling, sprouting and mural cell recruiting. Therefore, the interference of Ang2/Tie2 and VEGF/VEFGFR2 axes has attracted increasing attention for cancer prevention $(11,12)$. Indeed, several clinical trials of the dual target therapies have shown a more potent anticancer activity $(11,13)$. For instance, Ang2 and VEGFA bispecific antibody CrossMab has been clinically validated as an initial treatment for renal cell carcinoma (13).

Laggera alata is a member of genus Laggera (Compositae) and is a traditional herbal medicine with both antiinflammatory and anti-bacterial activities $(14,15)$. However, its anti-angiogenic efficacy is not known. Our group has isolated several eudesmane-type sesquiterpenes (ETSs) from Laggera alata (16). Two high-yield ETSs were selected to be evaluated for their anti-angiogenic activity. In the present study, both ETSs were found to be effective as angiogenic inhibitors, not only in the in vitro cell model but also in the in vivo zebrafish model. The mechanistic study showed that their anti-angiogenic effects were related to their interference in both the VEGF/VEGFR and the Ang2/Tie2 axes.

\section{Materials and methods}

Chemicals and reagents. Extraction and isolation of the two ETSs, $5 \alpha$-hydroxycostic acid (Comp. 1) and hydroxyisocostic acid (Comp. 2), from Laggera alata was carried out as described previously (16). Their structures are shown in Fig. 1A. The two chemicals were dissolved in DMSO at a final concentration of $50 \mathrm{mM}$ respectively, and diluted in culture medium to the indicated concentration for assigned assay. The vehicle group contained DMSO at $0.1 \%$ in its culture medium.

The human Ang2 was purchased from Adipogen (San Diego, CA, USA). VEGF (VEGFA-165) was obtained from Peprotech (Rockyhill, NJ, USA). The concentrations of Ang2 and VEGF used in the subsequent experiments were 400 and $20 \mathrm{ng} /$ ml, respectively. Fetal bovine serum (FBS), low serum growth supplement (LSGS), Dulbecco's modified Eagle's medium (DMEM), phosphatase substrate kit, BCA protein assay kit, Medium 200, Matrigel matrix, M-MLV and TRIzol reagent were all purchased from Thermo Fisher Scientific (Waltham, MA, USA), and Taq DNA polymerase was from Takara (Tokyo, Japan). Evagreen dye was purchased from Biotium (Hayward, CA, USA). Reagents including semaxanib (SU5416, a specific VEGFR inhibitor), phalloidin, heparin, bull serum albumin (BSA), MTT (3-(4,5-dimethylthiazol2-yl)-2,5-diphenyltetrazolium bromide) and non-protein chemicals were obtained from Sigma Chemical Co. (St. Louis, MO, USA). The pexmetinib (ARRY614, a specific inhibitor of Tie2 and p38) was purchased from APExBIO (Houston, TX, USA).
The antibodies against VEGFR, p-VEGFR $2_{\text {Tyr1175, }}$, p-Tie $2_{\text {Tyr992 }}$, AKT, p-AKT ${ }_{\text {Ser473 }}$, ERK1/2, p-ERK1/2 ${ }_{\text {Thr202/Tyr204, }}$, p38, p-p38 ${ }_{\text {Thr180/Tyr182 }}, \mathrm{p}-\mathrm{PLC} \gamma_{\mathrm{Ser} 1248}, \mathrm{p}-\mathrm{Src}_{\mathrm{Tyr} 416}, \mathrm{p}-\mathrm{FAK}_{\mathrm{Tyr} 397}$, p-eNOS ${ }_{\mathrm{Ser1177}}$, anti-mouse and anti-rabbit horseradish perioxidase (HRP)-conjugated secondary antibodies were purchased from Cell Signaling Technology (CST, Danvers, MA, USA). The antibodies against Tie2, and p-Tie $\left(\mathrm{Tie} 2_{\mathrm{Tyr} 992}+\mathrm{Tie}_{\mathrm{Ty} 1007}\right)$ were from Abcam (Cambridge, UK). The anti- $\beta$-actin antibody was obtained from Santa Cruz Biotechnology (Dallas, TX, USA). The antibody against E-cadherin was from BD Biosciences (BD, San Jose, CA, USA). Both DAPI and proteinase inhibitor cocktail tablets were from Roche (Basel, Switzerland).

Cell culture and zebrafish handling. Human umbilical vein endothelial cells (HUVECs) were purchased from Life Technologies Corp. (Carlsbad, CA, USA), and were cultured in the Medium 200 supplemented with LSGS, heparin $(0.1 \mathrm{mg} / \mathrm{ml})$, and heat-inactivated FBS $(20 \%$, v/v). The human breast cancer MCF-7 cells were obtained from the American Type Culture Collection (ATCC, Manassas, VA, USA), and were cultured in DMEM containing 10\% FBS. Both cell types were cultured in a $5 \% \mathrm{CO}_{2}$ humidified atmosphere at $37^{\circ} \mathrm{C}$. For some of the in vitro experiments, HUVECs were starved in both serum- and LSGS-free Medium 200 (maintenance medium) containing $0.5 \% \mathrm{BSA}$ for $4 \mathrm{~h}$, and MCF-7 cells were serum-starved in DMEM medium (maintenance medium) overnight $(\sim 8 \mathrm{~h})$. Then, the effects of ETSs were detected. Wild-type zebrafish (AB strain) were bought from Hong Kong goldfish market and maintained in flow-through aquaria at $28^{\circ} \mathrm{C}$. The fish were fed with general tropical fish food and brine shrimp. Embryos were collected by natural pairwise mating, and transferred to beakers $(25 \mathrm{fish} / 300 \mathrm{ml}$ beaker) with clean embryo water $(60 \mu \mathrm{g} / \mathrm{ml}$ instant ocean salt).

Cell proliferation assay. The cellular viability of the HUVECs in the presence of either ETS compound was assayed using the MTT method (17). In brief, HUVECs $\left(5 \times 10^{3}\right.$ cells/well) were seeded in 96-well plates and allowed to attach overnight. Cells were then treated with ETSs (from 25 to $200 \mu \mathrm{M}$ ) for $48 \mathrm{~h}$. The staining reagent of $30 \mu \mathrm{l}$ MTT $(5 \mathrm{mg} / \mathrm{ml})$ was added to each well for $4 \mathrm{~h}$. The medium was then removed and $200 \mu \mathrm{l}$ DMSO was added. After complete dissolution of the precipitated formazan, optical density was measured at $570 \mathrm{~nm}$ using a UV-VIS spectrophotometer (Genesys 5, Spectronic Instruments, USA). The cell viability was expressed as percentage $(\%)$ of the vehicle group.

The effect of ETSs on VEGF-induced HUVECs proliferation was also evaluated by MTT assay. Starved HUVECs $\left(5 \times 10^{3}\right.$ cells/well) were stimulated by VEGF in the presence or absence of the ETSs for $24 \mathrm{~h}$, then the effect of ETSs on the proliferation of HUVECs was evaluated.

Real-time PCR analysis. Total RNA in HUVECs or zebrafish embryos was isolated using TRIzol reagent and cDNA was conducted using M-MLV (18). Real-time PCR was performed on a Bio-Rad detection system CFX96 in a volume of $20 \mu \mathrm{l}$ containing Evagreen dye $1 \mu \mathrm{l}$, Taq polymerase $0.1 \mu \mathrm{l}$, cDNA $4 \mu \mathrm{l}(200 \mathrm{ng}), 1 \mu \mathrm{l}$ of each primer and $\mathrm{H}_{2} \mathrm{O} 12.9 \mu \mathrm{l}$. The reaction protocol was 40 cycles at $95^{\circ} \mathrm{C}$ for $20 \mathrm{sec}, 57^{\circ} \mathrm{C}$ for $20 \mathrm{sec}$, and 
A<smiles>C=C(C(=O)O)[C@@H]1CC[C@]2(C)CCCC(=C)[C@@]2(O)C1</smiles>

Comp. 1

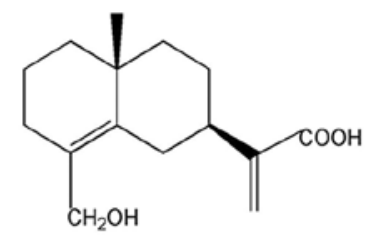

Comp. 2
B

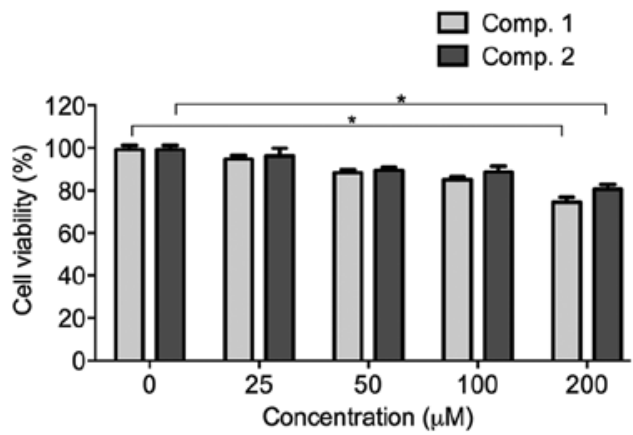

D

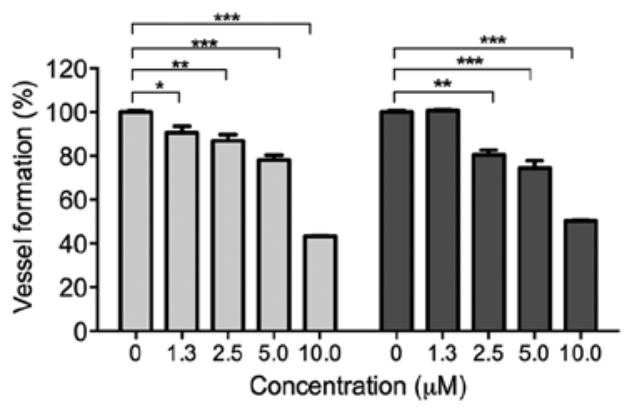

Figure 1. Effects of ETSs on VEGF-induced HUVEC proliferation and vessel formation in zebrafish embryos. (A) Chemical structure of the two ETSs, namely, $5 \alpha$-hydroxycostic acid (Comp. 1), hydroxyisocostic acid (Comp. 2). (B) Cytotoxicity of the ETSs on the HUVECs by MTT assay. (C) Concentration-dependent inhibitory effects of ETSs on VEGF-stimulated HUVECs proliferation. (D) Inhibition of the vessel formation was assessed by quantitative optical density of the endogenous alkaline phosphatase in zebrafish embryos. Each bar represents the mean $\pm \mathrm{SD}(\mathrm{n}=3),{ }^{* * *} \mathrm{p}<0.005 ;{ }^{* *} \mathrm{p}<0.01$ or ${ }^{*} \mathrm{p}<0.05$ for the comparisons between indicated groups.

$72^{\circ} \mathrm{C}$ for $20 \mathrm{sec}$. A melt curve analysis was performed at the end of the reaction to assess the specificity of amplification. The mRNA levels of the genes were normalized to the internal controls, namely, GAPDH and ELFI $\alpha$, in HUVECs and zebrafish, respectively. The primer sequences for HUVECs are as follows: $h G A P D H$ forward, 5'-CCCACTCCTCCACCT TTGAC-3' and reverse, 5'-TCTTCCTCTTGTGCTCTTGC-3'; hVEGFR2 forward, 5'-GGAACCTCACTATCCGCAGAGT-3' and reverse, 5'-CCAAGTTCGTCTTTTCCTGGGC-3'; hTiel forward, 5'-GACCCACACTGACCAACACA-3' and reverse, 5'-GTTGTGCACGTAGATGACGC-3'; hTie2 forward, 5'-CTG CAGTGCAATGAAGCATGC-3' and reverse, 5'-CTGCAGA CCCAAACTCCTGAG-3'. The primer sequences for zebrafish are as follows: $z E L F 1 \alpha$ forward, 5'-GGCTGACTGTGCTGT GCTGATTG-3' and reverse, 5'-CTTGTCGGT GGGACGGCT AGG-3'; zVEGFA-121 forward, 5'-CTACCCAGTGACCAA CGC-3' and reverse, 5'-GCTCTACAGCTCCTGACGAT-3'; zVEGFA-165 forward,5'-TGCTCCTGCAAATTCACACAA-3' and reverse, 5'-ATCTTGGCTTTTCACATCTGCAA-3'; zVEGFR2 forward, 5'-GCCTGATCCACAACTGCTTCC-3' and reverse, 5'-CTCTCCTCACACGACTCAATGC-3'; zAng2 5'-AGGTGGAGGCTGGACTGTC-3' and reverse, 5'-GTGG TGAGCAGGTGGATGAC-3'; zTiel forward, 5'-CAAGAGGC ACGGAAGGCTTA-3' and reverse, 5'-AGTGACAGTAAC GCAGAGCC-3'; zTie2 forward, 5'-CTACCCAGTGACCAA CGC-3' and reverse, 5'-GCTCTACAGCTC CTGACGAT-3'.

Wound-healing migration assay. The effect of the ETSs on cell migration was evaluated by the wound-healing assay according to protocols reported previously (19) with some modifications. Briefly, HUVECs and MCF-7 cells were plated in 24-well plates at a density of $2 \times 10^{5}$ and $2.5 \times 10^{5}$ cells/well, respectively. When the cells reached $100 \%$ confluence, they were starved to inactivate cell proliferation and a scrape was created with sterilized pipette tip. After washings twice with PBS, the cells were overlaid with fresh medium containing various concentrations of ETSs or SU5416 $(4 \mu \mathrm{M})$, co-treated with either VEGF or Ang2. Images were taken using an inverted microscope (Nikon TE300, Japan) at $0 \mathrm{~h}$ and after 20-h incubations. The extent of migration was analyzed using an Image-Pro Plus software (Media Cybernetics, USA). Wound size of the vehicle group was set as $100 \%$.

Capillary-like tube formation assay. Tube formation assay was carried out as described previously (20) with some modifications. In brief, HUVECs $\left(6 \times 10^{3}\right.$ cells/well) in the medium were seeded onto the Matrigel matrix-coated 96-well plates along with VEGF. Various dilutions of ETSs or SU5416 (4 $\mu \mathrm{M})$ were added to the wells and kept for $6 \mathrm{~h}$. The tubular structures were captured and quantified using an Image-Pro Plus software.

Immunofluorescent staining. HUVECs $\left(1 \times 10^{5}\right.$ cells $\left./ \mathrm{ml}\right)$ or MCF-7 cells $\left(2 \times 10^{5}\right.$ cells $\left./ \mathrm{ml}\right)$ were seeded to the clear cover glass-bottom 35-mm Petri-dishes for confocal imaging overnight at $37^{\circ} \mathrm{C}$ before starvation. During cell starvation, ETSs $(100 \mu \mathrm{M})$ were added to the cells $4 \mathrm{~h}$ before the cells were treated with either VEGF or Ang2 for specified duration (20 min to $6 \mathrm{~h}$ ) depending on the objective of the experiment. 
Collected cells were washed twice with ice-cold PBS, fixed with $4 \%$ paraformaldehyde for $15 \mathrm{~min}$, and permeabilized with $0.1 \%$ Triton X-100 in PBS. After rinsing twice with PBS, the cells were blocked in the $3 \%$ BSA in PBS for $1 \mathrm{~h}$ and immunostained with corresponding primary antibody at $4{ }^{\circ} \mathrm{C}$ overnight. Then, the cells were incubated with the secondary fluorescent antibody for $1 \mathrm{~h}$ at room temperature. Finally, the cell nucleus was visualized with DAPI, after washing with PBS, and images were captured using a confocal microscope (Olympus FV1000 IX81, Tokyo, Japan) (21).

Western blotting. HUVECs or MCF-7 cells $\left(1 \times 10^{6}\right.$ cells/dish) were seeded in $100-\mathrm{mm}$ culture dishes for $24 \mathrm{~h}$ before starvation. During cell starvation, ETSs were exposed to cells for $4 \mathrm{~h}$ and then stimulated with VEGF or Ang2 for specified time interval. Whole-cell extracts were collected using a lysis buffer supplemented with proteinase inhibitors. Protein concentration was measured using the $\mathrm{BCA}$ protein assay kit. Equal amounts of proteins $(40 \mu \mathrm{g})$ were resolved by electrophoresis on $12 \%$ SDS-PAGE gels and then transferred to PVDF membrane (Millipore, Billerica, MA, USA). The membrane was blocked with 3\% BSA at room temperature for $1 \mathrm{~h}$, incubated with primary antibody at $4^{\circ} \mathrm{C}$ overnight followed by HRP-conjugated goat secondary antibodies at room temperature for $1 \mathrm{~h}$. Protein bands were visualized using enhanced chemiluminescence detection reagents (Bio-Rad, Hercules, CA, USA) (22). The resulting images were scanned using a scanner (Canon PIXMA MP150, Japan).

Quantitative EAP assay. Wild-type zebrafish (AB strain) embryos were selected to evaluate the anti-angiogenic ability of ETSs in vivo, a quantitative endogenous alkaline phosphatase (EAP) assay was performed as described previously (18). Briefly, healthy, limpid, and regular embryos ( $24 \mathrm{~h}$ post fertilization, $24 \mathrm{hpf}$ ) were arrayed in a 96-well plate (1 embryo/well) and treated with ETSs $(1-10 \mu \mathrm{M})$ until $48 \mathrm{hpf}$. Embryos were then stained according to the manufacturer's instructions of the phosphatase substrate kit (Pierce, Waltham, MA, USA). The optical density of soluble end product was measured at $405 \mathrm{~nm}$ using a UV-VIS spectrophotometer. Vessel growth is presented as the percentage in optical density compared to that of the vehicle group: \% vessel formation $=(\mathrm{OD}$ treated at $48 \mathrm{hpf}$ - OD vehicle at $24 \mathrm{hpf}$ ) / (OD vehicle at $48 \mathrm{hpf}$ OD vehicle at $24 \mathrm{hpf}) \times 100 \%$.

Statistical analysis. All experiments were performed at least three times. Data are presented as the mean \pm standard deviation (SD). Statistical analysis was determined using one-way ANOVA.

\section{Results}

Effects of ETSs on the viability of HUVECs. The chemical structures of ETSs are shown in Fig. 1A. Before assessing the anti-angiogenic properties of ETSs, the MTT assay was used to evaluate their toxic effects on HUVECs in the normal growth medium. As shown in Fig. 1B, various concentrations $(0-100 \mu \mathrm{M})$ of ETSs were non-toxic to HUVECs. In this regard, the concentrations of ETSs $(\leq 100 \mu \mathrm{M})$ used in the subsequent in vitro experiments were considered non-toxic.
ETSs inhibits the proliferation of VEGF-induced HUVECs and vessel formation in zebrafish embryos. VEGF plays an important role during angiogenesis for its mitogenic effect on vascular endothelial cells (23). Therefore, we measured the inhibitory effect of ETSs on VEGF-induced HUVECs. The viability of HUVECs was upregulated significantly from 77.32 to $100 \%(p<0.005)$ when VEGF was added (Fig. 1C), while with the addition of ETSs, the viability was suppressed dose-dependently (Fig. 1C). At $25 \mu \mathrm{M}$ of Comp. 2, cell viability decreased to $97.21 \%(\mathrm{p}<0.05)$. A stronger inhibitory effect was shown by Comp. 1 with viability of $91.07 \%$ ( $<<0.01$ ). These data suggest that VEGF-induced proliferation of the HUVECs is sensitive to the presence of ETSs (Fig. 1B and C). Next, the anti-angiogenic activities of ETSs were examined in the wild-type zebrafish embryos. As shown in Fig. 1D, the two selected ETSs dose-dependently inhibited the vessel formation in the zebrafish embryos in the range of 1.3-10 $\mu \mathrm{M}$. At the concentration of $5 \mu \mathrm{M}$, both ETSs have exhibited very significant anti-angiogenic activities $(\mathrm{p}<0.005)$.

Both ETSs inhibit VEGF-induced HUVECs migration, stress fibers and tube formation. The effects of ETSs on VEGFmediated HUVECs migration were investigated using a wound-healing assay (Fig. 2A). HUVECs migrated to a clear area when stimulated with VEGF, and the stimulatory effect of VEGF was inhibited by ETSs in a dose-dependent manner (Fig. 2A). Even at $25 \mu \mathrm{M}$, the two compounds exhibited very significant inhibitory effects $(\mathrm{p}<0.005)$ (Fig. 2A). These data reveal that ETSs inhibit VEGF-stimulated migration of the endothelial cells.

The activation of endothelial cell migration by VEGF involves a massive remodeling of the actin cytoskeleton that reorganizes into transcytoplasmic stress fibers (24). As shown in Fig. 2B, the immunofluorescent intensity of F-actin (green) stained with FITC-conjugated phalloidin was highly increased in the VEGF-stimulated HUVECs, which indicated an increase of the stress fibers formation. However, such stress in the endothelial cells was markedly attenuated in the presence of ETSs (Fig. 2B). These results show that ETSs might suppress the migration of the VEGF-induced HUVECs by inhibiting the formation of the stress fiber.

During angiogenesis, a critical step is the formation of the new capillary tube derived from the migrated endothelial cells (4). Therefore, we investigated whether ETSs could inhibit VEGF-induced endothelial cell tube formation. As shown in Fig. 2C, a rough, but complete tube network was formed from the VEGF-stimulated HUVECs. However, with the treatment of ETSs $(100 \mu \mathrm{M})$, the tube formation pattern disassembled in a manner similar to that of the vehicle group ( $p>0.05$, data not shown). Quantification of the tube length revealed that $25 \mu \mathrm{M}$ ETSs could abolish the VEGF-stimulated tube formation significantly $(\mathrm{p}<0.05)(\mathrm{Fig} .2 \mathrm{C})$, suggesting a potent inhibitory effect of ETSs on the tubulogenesis of the VEGF-induced endothelial cells.

ETSs downregulate the pro-angiogenic-related genes in HUVECs and zebrafish embryos. The effects of ETSs on the angiogenic-related gene expression levels in HUVECs were evaluated by the real-time PCR analysis. HUVECs were exposed to ETSs $(50 \mu \mathrm{M})$ for $24 \mathrm{~h}$, the mRNA levels 
A
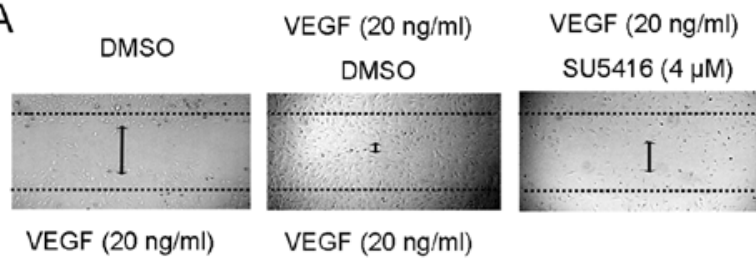

Comp. $1(100 \mu \mathrm{M})$

VEGF $(20 \mathrm{ng} / \mathrm{ml})$

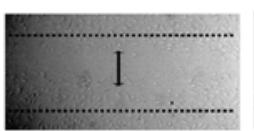

Comp. $2(100 \mu \mathrm{M})$
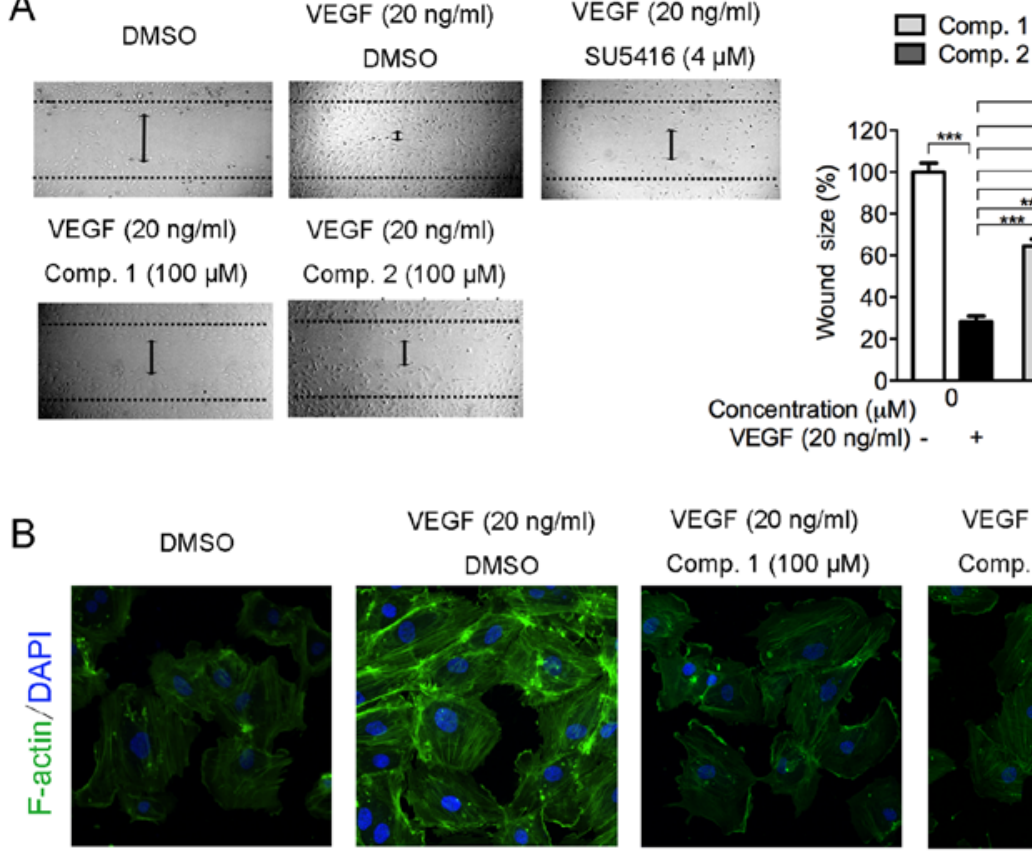

Comp. 2

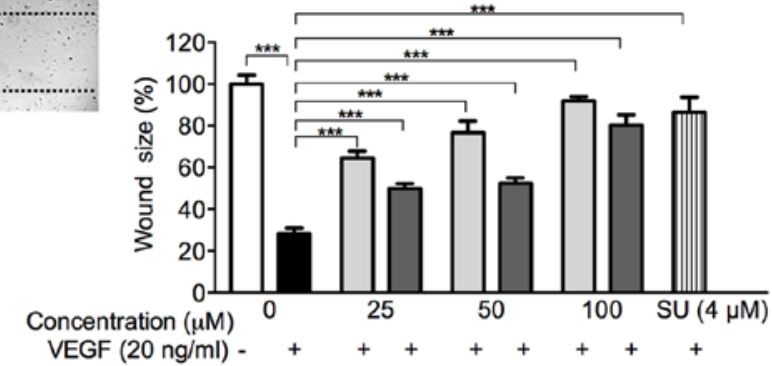

C

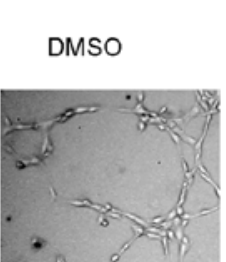

VEGF $(20 \mathrm{ng} / \mathrm{ml})$

VEGF $(20 \mathrm{ng} / \mathrm{ml})$

DMSO

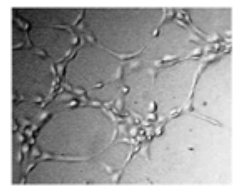

VEGF $(20 \mathrm{ng} / \mathrm{ml})$
SU5416 $(4 \mu \mathrm{M})$

Concentration $(\mu \mathrm{M})$ VEGF $(20 \mathrm{ng} / \mathrm{ml})$.

Comp. $1(100 \mu \mathrm{M})$

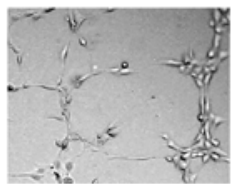

VEGF $(20 \mathrm{ng} / \mathrm{ml})$

Comp. $2(100 \mu \mathrm{M})$
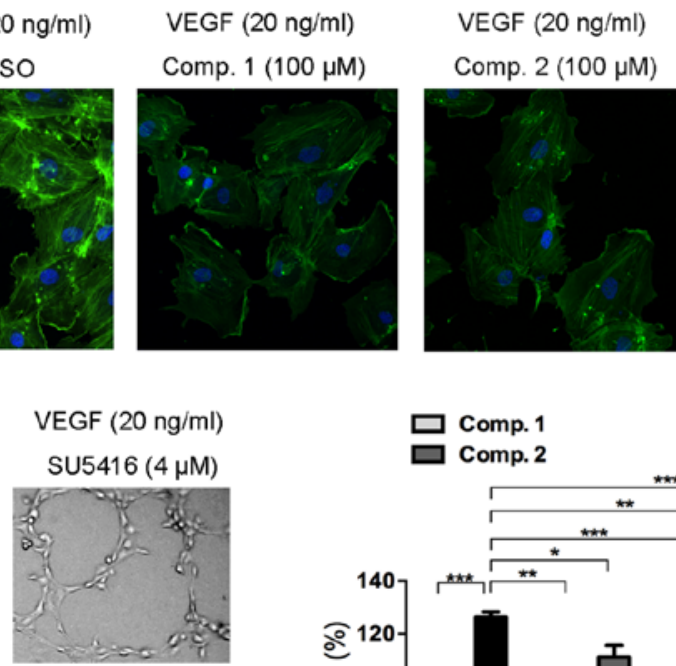

VEGF $(20 \mathrm{ng} / \mathrm{ml})$

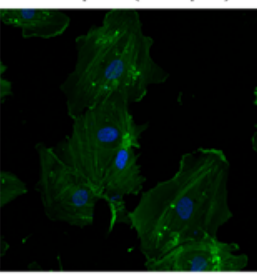

SU5416 $(4 \mu \mathrm{M})$
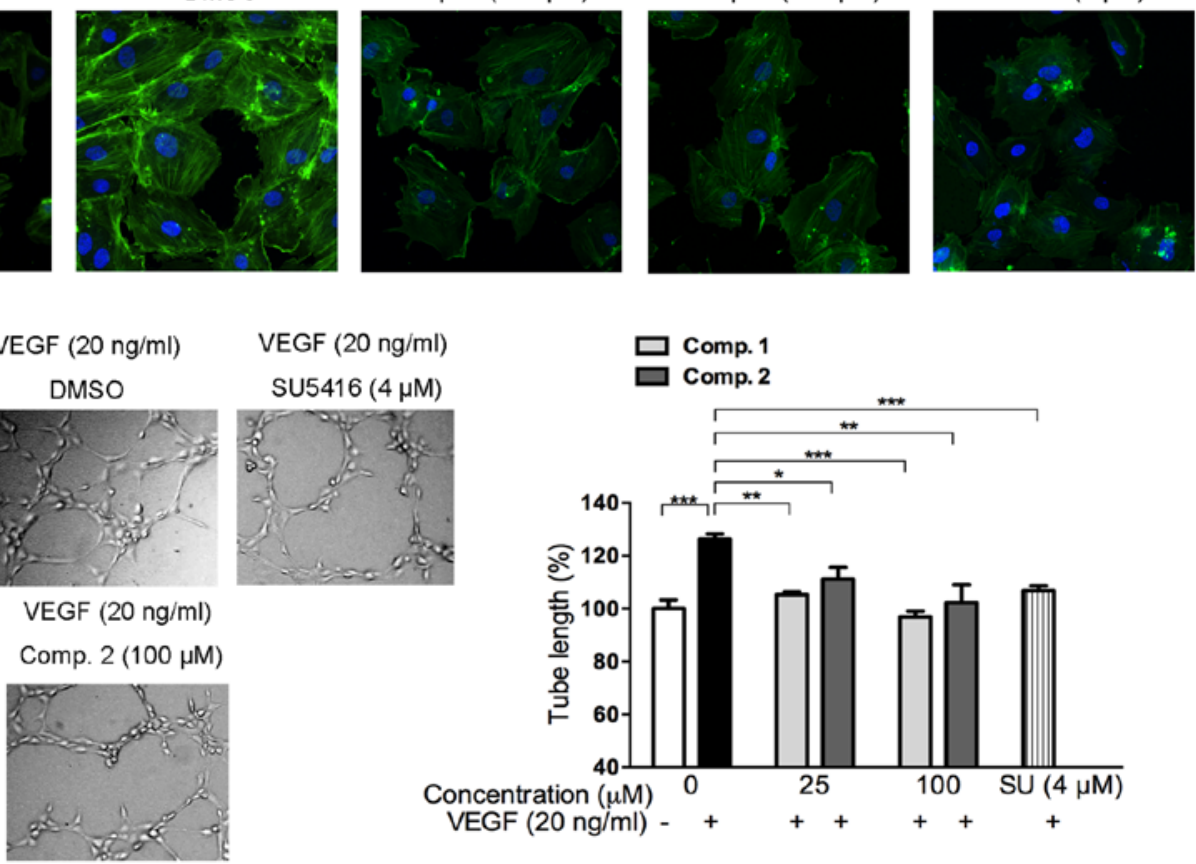

Figure 2. Effects of ETSs on VEGF-stimulated HUVEC migration, stress fibers and tube formation. (A) Effect of ETSs on VEGF-induced HUVECs migration. Starved HUVECs were subjected to wound-healing assay as described in Materials and methods (magnification, x100). (B) Effect of ETSs on VEGF-induced stress fibers formation in HUVECs. Immunofluorescent staining of HUVECs with FITC-conjugated phalloidin for F-actin (green) and DAPI (blue for nuclear). Starved HUVECs were treated with ETSs $(100 \mu \mathrm{M})$ or SU (SU5416, $4 \mu \mathrm{M})$ for $4 \mathrm{~h}$ and then stimulated with VEGF for 20 min, images were taken after immunostaining processes by confocal microscope (magnification, x1,200). (C) Inhibition of VEGF-induced HUVECs tube formation by ETSs or SU (SU5416). Cell tubular structures were captured (magnification, $\mathrm{x} 100)$ and tube length was quantified $(\mathrm{n}=3)$. Each bar represents the mean $\pm \mathrm{SD},{ }^{* * *} \mathrm{p}<0.005,{ }^{* *} \mathrm{p}<0.01,{ }^{*} \mathrm{p}<0.05$ for the comparison with cells exposed to VEGF only.

of VEGFR2 and Tiel/2 were then determined. As shown in Fig. 3A, both ETSs significantly inhibited the mRNA levels of VEGFR2 $(\mathrm{p}<0.005)$, the key receptor of VEGF. Only Comp. 1 downregulated the activity of the angiopoietin orphan receptor Tiel $(\mathrm{p}<0.01)$. However, both compounds significantly reduced the mRNA level of angiopoietin receptor Tie $2(\mathrm{p}<0.01$ or 0.005$)$. These data suggest that ETSs apparently acted as inhibitors of angiogenesis by regulating VEGF/VEGFR2 and Ang2/Tie2 pathways. Thus, the following results from in vivo experiment focused on the two pathways.

To determine the effects of ETSs on the pro-angiogenicrelated gene expression levels in vivo, zebrafish embryos were treated with ETSs $(10 \mu \mathrm{M})$ for $24 \mathrm{~h}$ and subjected to real-time PCR analysis. As shown in Fig. 3B, the mRNA levels of both $V E G F A$ and $V E G F R 2$ were downregulated significantly in the presence of ETSs. As for the Ang2/Tie axis, ETSs down- regulated the mRNA levels of Ang2 ( $<<0.01$ or $\mathrm{p}<0.005)$ and Tie2 receptor $(\mathrm{p}<0.01)$, but no significance was found in Tie1 (Fig. 3B). The PCR data from the zebrafish embryos further confirmed their anti-angiogenic activities.

ETSs inhibit the activation of VEGF/VEGFR2 signaling pathways in HUVECs. Our previous results proved that ETSs effectively suppressed VEGF-stimulated angiogenesis both in vitro and in vivo. To understand the molecular mechanism of ETS-induced inhibition of angiogenesis, we investigated whether ETSs suppressed the phosphorylation of VEGFR2, the critical receptor tyrosine kinase on the surface of endothelial cells (25). The addition of exogenous VEGF to HUVECs strongly increased the phosphorylation of VEGFR2 at Ser1175 site (Fig. 4). However, pretreatment with ETSs suppressed the VEGF-stimulated VEGFR2 phosphorylation (Fig. 4). 

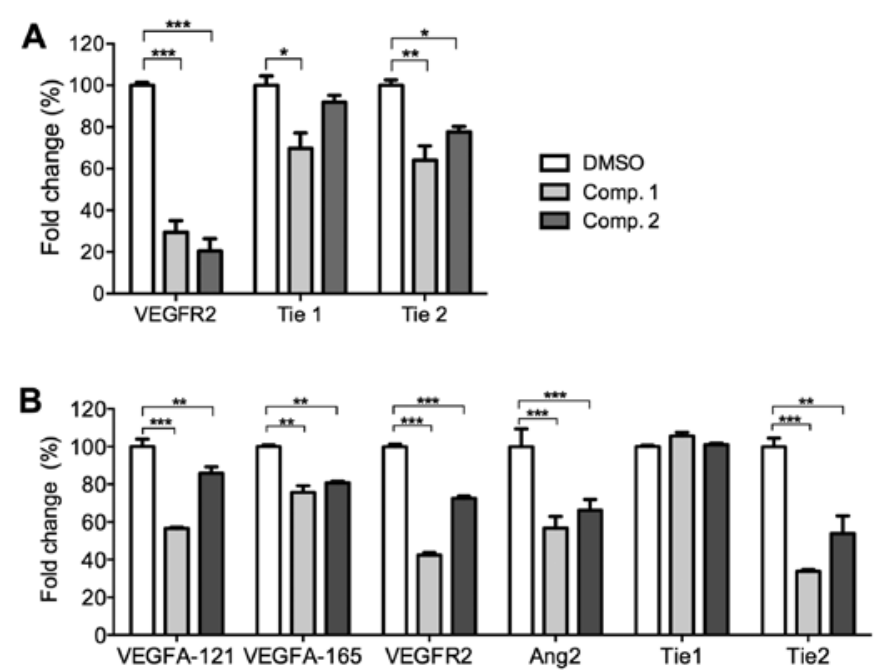

Figure 3. Effects of ETSs on mRNA level of angiogenic-related genes in HUVECs and zebrafish embryos. (A) HUVECs were exposed to DMSO or ETS $(50 \mu \mathrm{M})$-containing medium for $24 \mathrm{~h}$, the mRNA levels of the markers were analyzed by real-time PCR. (B) mRNA levels of pro-angiogenic-related genes in the vehicle or ETS $(10 \mu \mathrm{M})$-treated zebrafish embryos. Each bar represents the mean $\pm \mathrm{SD}(\mathrm{n}=3),{ }^{* * *} \mathrm{p}<0.005 ;{ }^{* *} \mathrm{p}<0.01,{ }^{*} \mathrm{p}<0.05$ for the comparison with vehicle group.

VEGF binding to VEGFR2 activates various downstream signaling molecules with distinct and overlapping functions, which is responsible for endothelial cell proliferation, migration and tube formation $(5,26)$. Therefore, we explored whether ETSs inhibited VEGF/VEGFR2-mediated signaling pathways. Starved HUVECs were pretreated with ETSs for $4 \mathrm{~h}$ and subsequently stimulated by VEGF for $20 \mathrm{~min}$. As shown in Fig. 4, an extensive downregulation of the activation of Src/AKT/eNOS signaling pathway was observed at $50 \mu \mathrm{M}$ ETSs (Fig. 4). ETSs also suppressed the activation of the VEGFR2 downstream signaling molecules, namely, FAK, PLC $\gamma$, ERK1/2 and p38. Taken together, these data suggested that ETSs suppressed angiogenesis by inhibiting the VEGF/VEGFR2-mediated Src/AKT/eNOS, FAK, PLC $\gamma /$ ERK1/2, and p38 signaling pathways.

ETSs downregulate VEGF-enhanced Ang2 mRNA level in HUVECs. With the stimulation of VEGF in endothelial cells, the mRNA level of Ang2, another crucial pro-angiogenic factor, increased (11). As shown in Fig. 5, in the presence of VEGF, the Ang2 mRNA level increased significantly compared to the vehicle. Pretreatment by ETSs $(50 \mu \mathrm{M})$ almost completely reversed the increase induced by VEGF $(\mathrm{p}<0.001)$. VEGF induced Ang2 secretion and synthesis, this Ang2 could bind with Tie2 and promote the angiogenic activity of VEGF. The low Ang2 level of ETS-treated group may indicate that Ang2/Tie2 might have taken part in the ETS-induced antiangiogenesis. To clarify the direct effects of ETSs on Ang2/ Tie2 axis, we completed the following experiments.

ETSs inhibit Ang2-induced phosphorylation of Tie receptor. Ang2 acts as an agonist of Tie2 receptor and leads to the phosphorylation of Tie2. This would result in vascular destabilization and remodeling (22). Hence, we utilized exogenous Ang2 to induce Tie2 phosphorylation, while the activation of

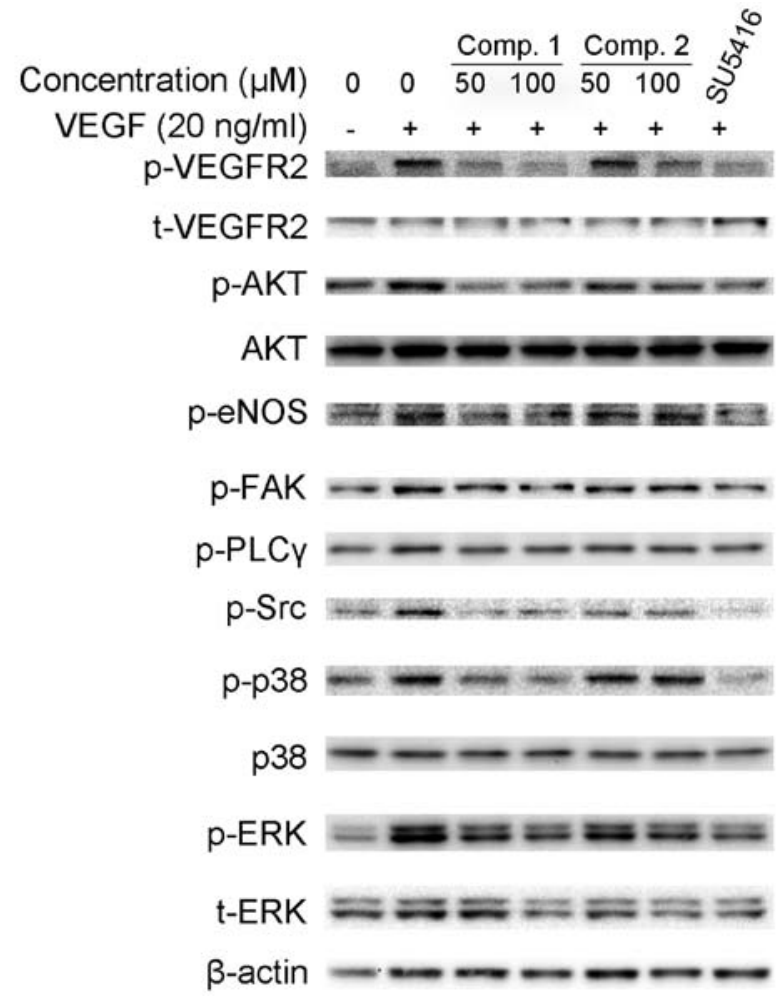

Figure 4. ETSs suppress VEGF/VEGFR2 signaling pathways in HUVECS Starved HUVECs were pretreated with ETSs or SU5416 $(4 \mu \mathrm{M})$ for $4 \mathrm{~h}$ and then stimulated with VEGF for $20 \mathrm{~min}$. Protein from different treatments was evaluated by western blotting and probed with these specific antibodies. Three independent experiments were performed.

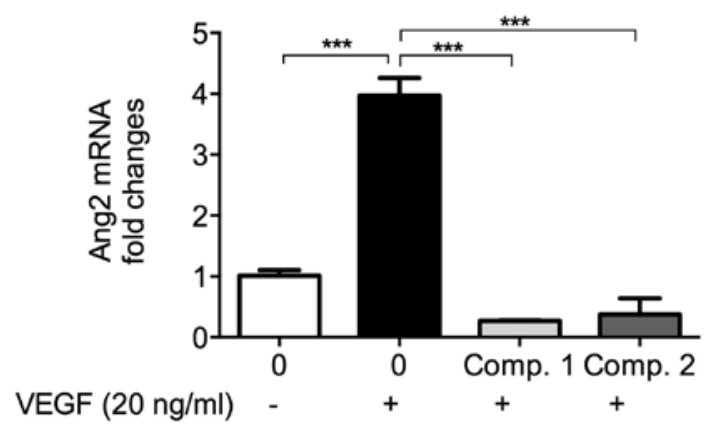

Figure 5. Effects of ETSs on Ang2 mRNA levels of VEGF-stimulated HUVECs determined by real-time PCR. Total RNAs were prepared from HUVECs that had been treated with VEGF with or without the presence of ETSs $(50 \mu \mathrm{M})$ for $6 \mathrm{~h}$. Each bar represents the mean $\pm \mathrm{SD}(\mathrm{n}=3),{ }^{* * *} \mathrm{p}<0.005$ for the comparison with cells exposed to VEGF only.

Tie2 in the presence of ETSs was evaluated by both immunofluorescent staining and the western blotting. Starved HUVECs were pretreated with ETSs $(100 \mu \mathrm{M})$ for $4 \mathrm{~h}$ and stimulated with Ang2 for $30 \mathrm{~min}$. Compared to the vehicle group (DMSO-treated), Ang2 increased the phosphorylation of Tie which occurred on the cell membrane (Fig. 6A). However, for the group treated with ETSs $(100 \mu \mathrm{M})$, they showed weaker fluorescence intensity than that with only the Ang2 stimulation, indicative of the inhibition of the phosphorylation of Tie receptor in the presence of ETSs. In the western blotting results (Fig. 6B), the data showed the inhibitory effects of ETSs on Ang2-induced Tie2 phosphorylation. 

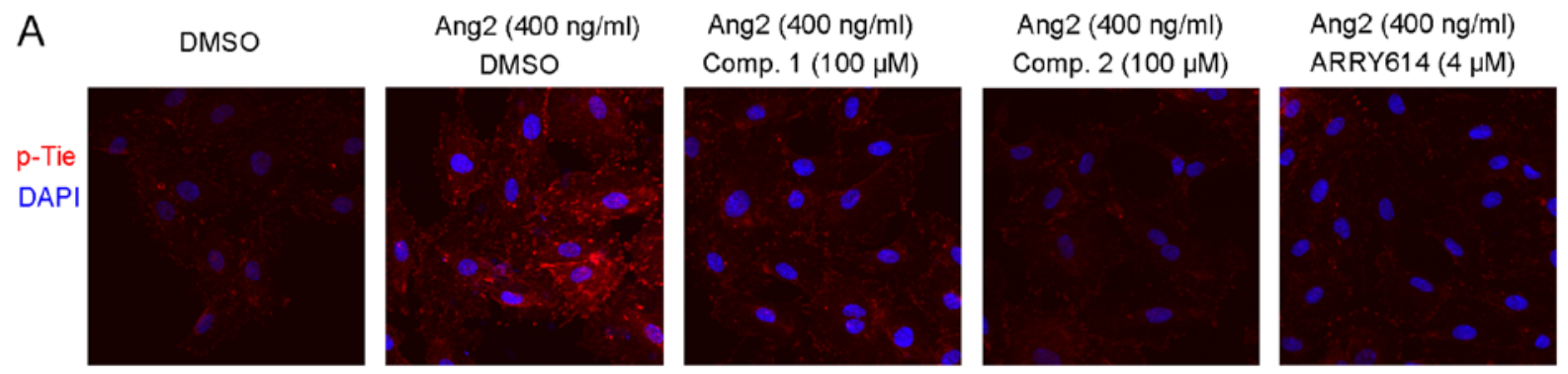

B

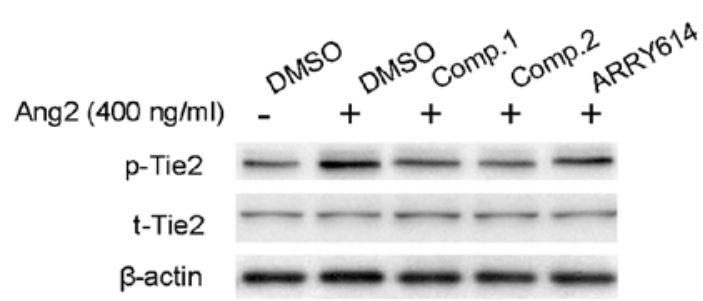

Figure 6. ETSs inhibit Ang2-induced Tie2 phosphorylation in HUVECs by immunofluorescent staining (A) and western blot analysis (B). Starved HUVECs were cultured with ETSs $(100 \mu \mathrm{M})$ or ARRY614 $(4 \mu \mathrm{M})$ for $4 \mathrm{~h}$ and stimulated with Ang2 (400 $\mathrm{ng} / \mathrm{ml})$ for $30 \mathrm{~min}$. (A) The treated HUVECs were immunostained with anti-pTie (Tie2 Tyr992 + Tie1 Tyr1007) antibody. Images of p-Tie (red) and the merged images with DAPI (blue) are shown with magnification, x1,200. (B) p-Tie2 levels in treated HUVECs were evaluated by western blotting.

A
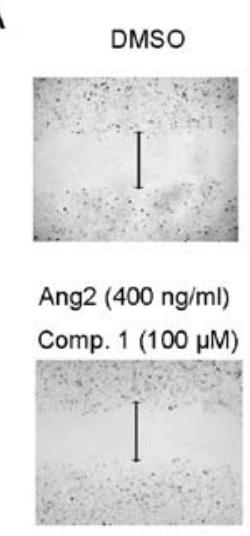

B

DMSO

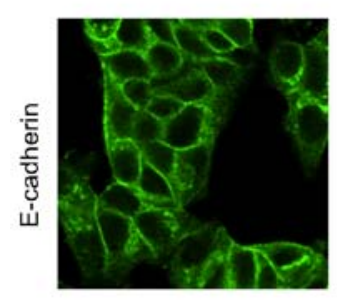

C
Ang2 $(400 \mathrm{ng} / \mathrm{ml}) \quad$ Ang2 $(400 \mathrm{ng} / \mathrm{ml})$

DMSO

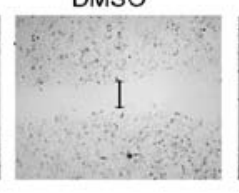

Ang2 $(400 \mathrm{ng} / \mathrm{ml})$
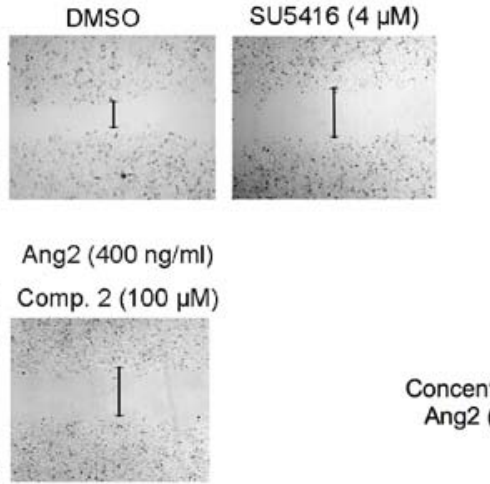

Concentration $(\mu \mathrm{M}) 0$ Ang2 (400 ng/ml) -

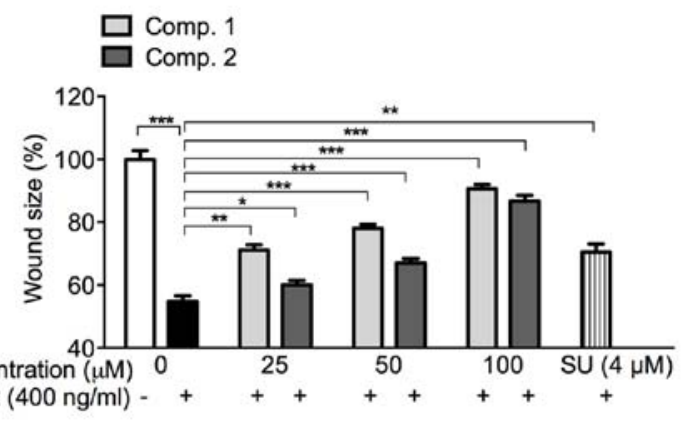

Ang2 $(400 \mathrm{ng} / \mathrm{ml})$

Comp. $1(100 \mu \mathrm{M})$

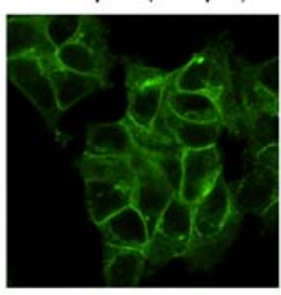

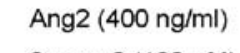

Comp. $2(100 \mu \mathrm{M})$

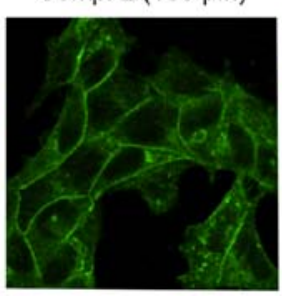

Ang2 $(400 \mathrm{ng} / \mathrm{ml})$

ARRY614 $(4 \mu \mathrm{M})$

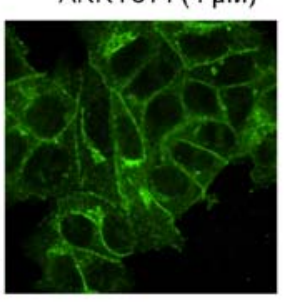

Ang2 (400 ng/ml)
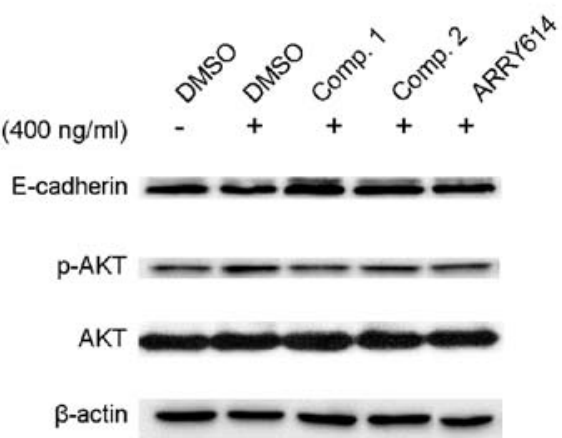

Figure 7. Inhibition of ETSs on Ang2-stimulated MCF-7 cell migration and E-cadherin loss. (A) ETSs suppress Ang2-induced MCF-7 cells migration (magnification, $x 100)$. Each bar represents the mean $\pm \mathrm{SD}(\mathrm{n}=3)$ of the wound size, ${ }^{* * * *} \mathrm{p}<0.005 ;{ }^{* * *} \mathrm{p}<0.01$ and ${ }^{*} \mathrm{p}<0.01$ for the comparison with cells exposed to Ang2 only. (B and C) Starved MCF-7 cells stimulated with Ang2 with or without ETSs for $8 \mathrm{~h}$, then cells were fluorescent stained with E-cadherin and images were taken with magnification, $x 1,200$ (B), or the whole cell protein of the treated cells was extracted for subsequent western blot analyses (C). 


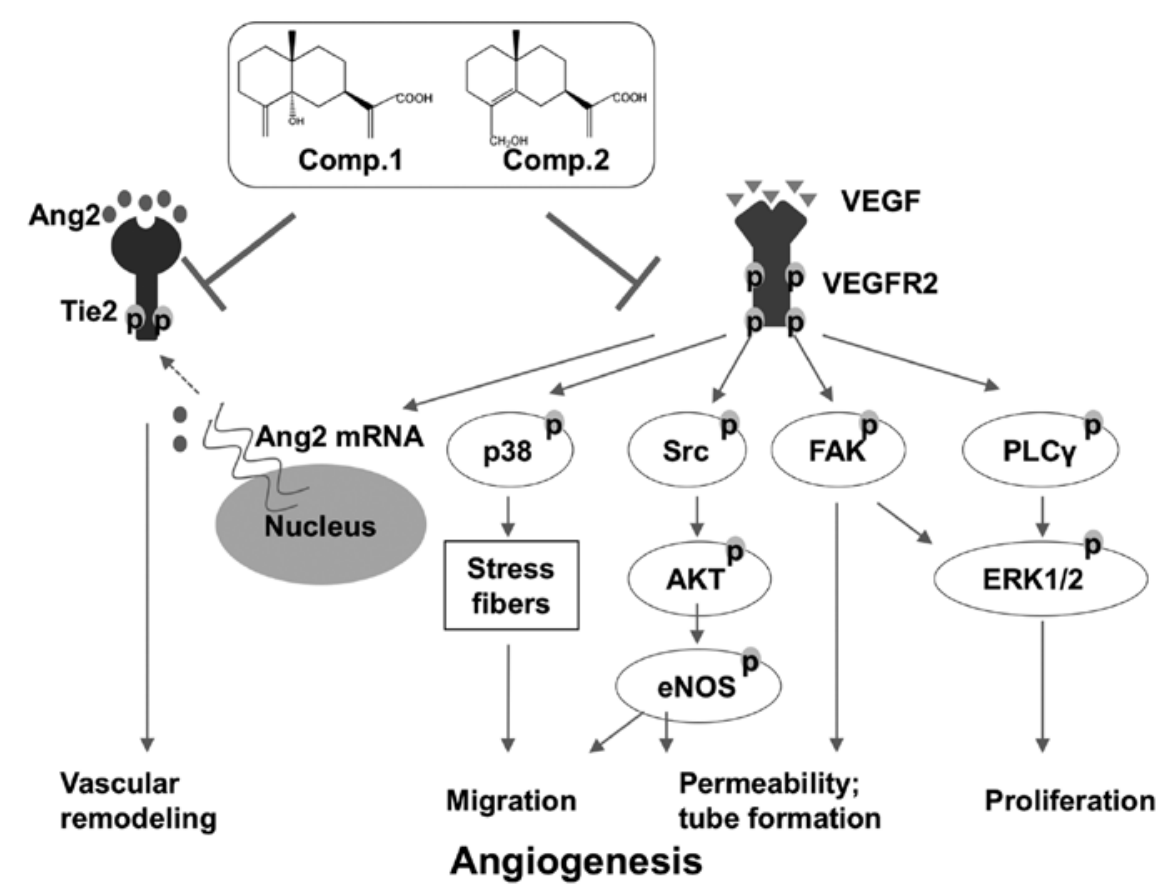

Figure 8. The ETS modulation of angiogenesis in HUVECs. Arrows, activation; blocks, the inhibitory effect of ETSs.

ETSs inhibit Ang2-induced MCF-7 cell migration. Ang2 promotes the proangiogenic action of VEGF leading to blood vessel growth. Besides, Ang2 also enhances tumor growth and cancerous metastasis (27). In order to evaluate whether ETSs could inhibit Ang2 stimulated cancer cell migration, we conducted wound-healing analysis on breast cancer MCF-7 cells. Data revealed that stimulation with Ang2 (400 ng/ml) highly enhanced cell mobility, leading to smaller wound area (Fig. 7A). However, ETSs inhibited Ang2-induced MCF7 cells migration dose-dependently from 25 to $100 \mu \mathrm{M}$. At $25 \mu \mathrm{M}$ of ETSs, Comp. 1 exhibited stronger inhibitory effect with larger wound area $(p<0.005)$ than that of Comp. 2 (Fig. 7A).

E-cadherin is a cell-cell adhesion molecule with pivotal roles in tissue formation, epithelial cells behavior, and is linked to the invasion of cancer cells (28). With the stimulation of Ang2 on MCF-7 cells, we observed the loss of E-cadherin (Fig. 7B). Western blot assay of the E-cadherin protein level also confirmed the loss of E-cadherin induced by Ang2 (Fig. 7C). However, ETS treatment suppressed the E-cadherin loss, both immunofluorescent staining and western blot analysis showed the inhibitory effect of ETSs. Besides, the p-AKT level was upregulated after Ang2 stimulation in MCF-7 cells, while the ETS exposed cells showed a sharp reduction of the p-AKT level (Fig. 7C). These data suggested that ETSs inhibited Ang2-induced MCF-7 cell migration by suppressing E-cadherin loss and AKT phosphorylation.

\section{Discussion}

Tumor growth is initially fed by the nearby blood vessels in order to support the removal of waste from and supply of nutrients to a tumor (29). Therefore, anti-angiogenic therapy has been considered as a promising method to treat cancer. Search for the appropriate angiogenic inhibitors is a key step towards achieving this goal (6). In the present study, to the best of our knowledge, we show for the first time that ETSs exhibited anti-angiogenic properties both in vivo and in vitro.

Several activators in the angiogenic process have been identified in many pro-angiogenic mechanisms. The VEGF/VEGFR signaling pathway has been implicated as a critical regulator of tumor neovasculation (7). In this study, VEGF-stimulated HUVEC proliferation, migration, and tube formation were inhibited dose-dependently by the ETSs at the non-toxic concentrations (Figs. 1C and 2). Moreover, ETSs inhibited the VEGF-induced VEGFR2 phosphorylation in HUVECs (Fig. 4), suggesting that the ETSs may likely function as VEGF/VEGFR2 inhibitors suppressing the VEGF-stimulated angiogenesis.

Due to the strong tyrosine kinase activity of VEGFR2, it transduces a series of downstream cascades in the angiogenic process (30). AKT is a serine/threonine kinase, a well-known VEGFR2 signaling downstream mediator that plays a central role in a range of cellular functions including cancer cell growth, migration, and angiogenesis (31). AKT/eNOS signaling has been identified as a functional mediator in the VEGF-stimulated angiogenesis, through the production of NO to mediate cell cytoskeleton reorganization and increase vascular permeability (31-33). Moreover, the function of AKT/ eNOS in the activation of VEGFR2 signaling pathway depends on its upstream Src activation (34). Treatment with ETSs has shown a sharp decrease in the phosphorylation of $\operatorname{Src}_{\text {Tyr416 }}$,

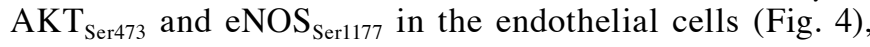
suggesting that the Src/AKT/eNOS pathway was involved in the ETS-mediated anti-angiogenic molecular mechanism. VEGF/VEGFR2 system activates its downstream molecules, including FAK and PLC $\gamma$ to facilitate proliferation, migration and morphogenic differentiation of endothelial cells into capillary-like structures with vascular permeability $(35,36)$. VEGF relies on the activation of FAK to promote tumor vascular permeability, progression, and metastasis (37). On 
the other hand, FAK partially promotes ERK1/2 signaling cascade which is very important for vascular endothelial cell proliferation after VEGF-recruited PLC $\gamma$ is activated $(35,38)$. In our study, we observed that ETSs inhibited endothelial cell proliferation and tube formation in response to VEGF treatment, and with a sharp decrease in FAK, ERK1/2 and PLC $\gamma$ (Fig. 4), indicating that ETSs suppressed the key steps of VEGF-stimulated endothelial cells by inactivating FAK and PLC $\gamma /$ ERK1/2 signaling pathways. p38 was identified as an important player in VEGF-induced endothelial cell mobility by promoting the formation of stress fibers (24). Our results showed that ETSs reduced significantly the formation of VEGF-induced stress fibers and the phosphorylation of $\mathrm{p} 38$ (Figs. 2B and 4), suggesting that ETSs inhibited p38 activation to disrupt VEGF-induced stress fiber formation. These mechanistic results reveal that ETSs inhibited the activation of VEGFR2 and thereby suppressed the VEGFR2 downstream signaling pathways in the endothelial cells.

Anti-VEGF and VEGFR2 drugs have been used clinically and were shown to slow tumor growth, improve drug delivery, and more importantly, to extend the lives of cancer patients, but drug resistance of the inhibitors in the VEGF/VEGFR2 system limits their clinical application (39). Thus, other strategies for inhibiting the tumor neovascularization are being sought. Mechanistic studies of the resistance showed that anti-VEGF therapy involved the adaptive enforcement of Ang2/Tie2 system $(12,40)$. Mounting evidence suggests that combination of both anti-VEGF/VEGFR and Ang2/Tie2 agents targeting the blood vessel network can lead to outcomes superior to those using either agent alone $(8,41)$.

It is well documented that VEGF upregulates the mRNA level of Ang2 in endothelial cells and leads to Ang2 secretion $(9,11)$. The secreted Ang2 acts as a partial agonist of Tie2 receptor leading to Tie2 phosphorylation, disturbances of vascular endothelial cell junction integrity and vascular sprouting $(11,40,42)$. In the present study, VEGF upregulated the mRNA level of Ang2 but was suppressed by ETSs (Fig. 5). Besides, ETSs reduced exogenous Ang2-induced Tie2 phosphorylation in endothelial cells (Fig. 6). Our results indicated that ETSs not only suppressed VEGF/VEGFR2 axis but also the Ang2/Tie2 system in the endothelial cells. This makes ETSs promising anti-angiogenic candidates with dual targets.

Higher circulating amount of Ang2 was detected in the plasma of cancer patients at the advanced stage, and Ang2 facilitated the metastatic ability of cancer cells, such as breast and ovarian cancers (43). MCF-7 cells have a weak metastatic ability, but Ang2 can upregulate their mobility in tumor-bearing mice and cells. E-cadherin is a cell-cell adhesion molecule with pivotal roles in tissue formation, epithelial cell behavior and suppression of cancer, and it is linked to the invasion of breast cancer cells (28). We have observed that ETSs showed a sharp reduction in the migration of Ang2-induced MCF-7 cells, suppression of the loss in E-cadherin, and decrease in the expression of p-AKT (Fig. 7).

To further ascertain the anti-angiogenic effects by ETSs, in vivo experiments were conducted in the zebrafish embryo which is a successful animal model for studying angiogenesis and evaluating anti-angiogenic agents $(44,45)$. Small molecules added directly to the culture media containing the zebrafish embryos could diffuse into the embryos and induce angio- genic effect (44). Our results demonstrated that exposure of ETSs altered the process of angiogenesis in zebrafish embryos (Figs. 1D and 3B). Therefore, the two compounds exhibited anti-angiogenic activities in vivo.

In conclusion, we provide evidence in the present study that ETSs inhibited the proliferation, migration and tube formation in VEGF-induced HUVECs. Suppressing the VEGF/VEGFR2 system following the treatment with ETSs could result in the multiple inhibitions of a number of downstream VEGF-dependent pathways, including Src/AKT/eNOS, FAK, PLC $\gamma /$ ERK1/2 and p38 pathways, and contribute to ETS-mediated anti-angiogenic property (Fig. 8). Furthermore, ETSs effectively block Ang2/Tie2 axis, implying that ETSs may function as angiogenic inhibitors with dual targets (Fig. 8). Collectively, these findings suggest that the ETSs may be developed into a new type of anti-angiogenic agent for the treatment of breast cancer.

\section{Acknowledgements}

This study was supported in part by the CUHK grants (3132789 and FACULTY-P17179).

\section{References}

1. Folkman J: Fighting cancer by attacking its blood supply. Sci Am 275: 150-154, 1996.

2. Folkman J: Angiogenesis. Annu Rev Med 57: 1-18, 2006.

3. Ferrara N and Kerbel RS: Angiogenesis as a therapeutic target. Nature 438: 967-974, 2005.

4. Herbert SP and Stainier DY: Molecular control of endothelial cell behaviour during blood vessel morphogenesis. Nat Rev Mol Cell Biol 12: 551-564, 2011.

5. Taimeh Z, Loughran J, Birks EJ and Bolli R: Vascular endothelial growth factor in heart failure. Nat Rev Cardiol 10: 519-530, 2013.

6. Jayson GC, Kerbel R, Ellis LM and Harris AL: Antiangiogenic therapy in oncology: Current status and future directions. Lancet 388: 518-529, 2016.

7. Carmeliet $P$ and Jain RK: Molecular mechanisms and clinical applications of angiogenesis. Nature 473: 298-307, 2011.

8. Biel NM and Siemann DW: Targeting the angiopoietin-2/Tie-2 axis in conjunction with VEGF signal interference. Cancer Lett 380: 525-533 2016

9. Augustin HG, Koh GY, Thurston G and Alitalo K: Control of vascular morphogenesis and homeostasis through the angiopoietin-Tie system. Nat Rev Mol Cell Biol 10: 165-177, 2009.

10. Fagiani E and Christofori G: Angiopoietins in angiogenesis. Cancer Lett 328: 18-26, 2013.

11. Gerald D, Chintharlapalli S, Augustin HG and Benjamin LE: Angiopoietin-2: An attractive target for improved antiangiogenic tumor therapy. Cancer Res 73: 1649-1657, 2013.

12. Rigamonti N, Kadioglu E, Keklikoglou I, Wyser Rmili C, Leow CC and De Palma M: Role of angiopoietin-2 in adaptive tumor resistance to VEGF signaling blockade. Cell Rep 8: 696-706, 2014.

13. Kienast Y, Klein C, Scheuer W, Raemsch R, Lorenzon E, Bernicke D, Herting F, Yu S, The HH, Martarello L, et al: Ang-2VEGF-A CrossMab, a novel bispecific human IgG1 antibody blocking VEGF-A and Ang-2 functions simultaneously, mediates potent antitumor, antiangiogenic, and antimetastatic efficacy. Clin Cancer Res 19: 6730-6740, 2013.

14. Wu YH, Zhang XM, Hu MH, Wu XM and Zhao Y: Effect of Laggera alata on hepatocyte damage induced by carbon tetrachloride in vitro and in vivo. J Ethnopharmacol 126: 50-56, 2009.

15. Wu Y, Zhou C, Song L, Li X, Shi S, Mo J, Chen H, Bai H, Wu X, Zhao J, et al: Effect of total phenolics from Laggera alata on acute and chronic inflammation models. J Ethnopharmacol 108: 243-250, 2006

16. Wang GC, Li GQ, Geng HW, Li T, Xu JJ, Ma F, Wu X, Ye WC and Li YL: Eudesmane-type sesquiterpene derivatives from Laggera alata. Phytochemistry 96: 201-207, 2013. 
17. Pratheeshkumar P, Budhraja A, Son YO, Wang X, Zhang Z, Ding S, Wang L, Hitron A, Lee JC, Xu M, et al: Quercetin inhibits angiogenesis mediated human prostate tumor growth by targeting VEGFR- 2 regulated AKT/mTOR/P70S6K signaling pathways. PLoS One 7: e47516, 2012.

18. Huang W, Wang J, Liang Y, Ge W, Wang G, Li Y and Chung HY: Potent anti-angiogenic component in Croton crassifolius and its mechanism of action. J Ethnopharmacol 175: 185-191, 2015.

19. Li M, Wu S, Liu Z, Zhang W, Xu J, Wang Y, Liu J, Zhang D, Tian H, Li Y, et al: Arenobufagin, a bufadienolide compound from toad venom, inhibits VEGF-mediated angiogenesis through suppression of VEGFR-2 signaling pathway. Biochem Pharmacol 83: 1251-1260, 2012.

20. Lin S, Ching LT, Chen J and Cheung PCK: Antioxidant and antiangiogenic effects of mushroom phenolics-rich fractions. J Funct Foods 17: 802-815, 2015

21. Li H, Li M, Wang G, Shao F, Chen W, Xia C, Wang S, Li Y, Zhou G and Liu Z: EM23, A natural sesquiterpene lactone from Elephantopus mollis, induces apoptosis in human myeloid leukemia cells through thioredoxin- and reactive oxygen speciesmediated signaling pathways. Front Pharmacol 7: 77, 2016.

22. Bogdanovic E, Nguyen VP and Dumont DJ: Activation of Tie2 by angiopoietin-1 and angiopoietin-2 results in their release and receptor internalization. J Cell Sci 119: 3551-3560, 2006.

23. Robert S and Kerbel PD: Tumor angiogenesis. N Engl J Med 358: 2039-2049 2008.

24. Rousseau S, Houle F, Kotanides H, Witte L, Waltenberger J, Landry $\mathrm{J}$ and Huot J: Vascular endothelial growth factor (VEGF)-driven actin-based motility is mediated by VEGFR2 and requires concerted activation of stress-activated protein kinase 2 (SAPK2/p38) and geldanamycin-sensitive phosphorylation of focal adhesion kinase. J Biol Chem 275: 10661-10672, 2000.

25. Shibuya M: VEGF-VEGFR signals in health and disease. Biomol Ther (Seoul) 22: 1-9, 2014.

26. Ha CH, Bennett AM and Jin ZG: A novel role of vascular endothelial cadherin in modulating c-Src activation and downstream signaling of vascular endothelial growth factor. J Biol Chem 283 7261-7270, 2008

27. Eroglu Z, Stein CA and Pal SK: Targeting angiopoietin-2 signaling in cancer therapy. Expert Opin Investig Drugs 22 : $813-825,2013$.

28. Onder TT, Gupta PB, Mani SA, Yang J, Lander ES and Weinberg RA: Loss of E-cadherin promotes metastasis via multiple downstream transcriptional pathways. Cancer Res 68: 3645-3654, 2008.

29. Hanahan D and Weinberg RA: Hallmarks of cancer: The next generation. Cell 144: 646-674, 2011.

30. Wahl O, Oswald M, Tretzel L, Herres E, Arend J and Efferth T: Inhibition of tumor angiogenesis by antibodies, synthetic smal molecules and natural products. Curr Med Chem 18: 3136-3155, 2011.
31. Chen X, Zhao M, Hao M, Sun X, Wang J, Mao Y, Zu L, Liu J, Shen Y, Wang J, et al: Dual inhibition of PI3K and mTOR mitigates compensatory AKT activation and improves tamoxifen response in breast cancer. Mol Cancer Res 11: 1269-1278, 2013.

32. Ying L and Hofseth LJ: An emerging role for endothelial nitric oxide synthase in chronic inflammation and cancer. Cancer Res 67: 1407-1410, 2007

33. Lim KH, Ancrile BB, Kashatus DF and Counter CM: Tumour maintenance is mediated by eNOS. Nature 452: 646-649, 2008.

34. Di Lorenzo A, Lin MI, Murata T, Landskroner-Eiger S Schleicher M, Kothiya M, Iwakiri Y, Yu J, Huang PL and Sessa WC: eNOS-derived nitric oxide regulates endothelial barrier function through VE-cadherin and Rho GTPases. J Cell Sci 126: 5541-5552, 2013.

35. Sulzmaier FJ, Jean C and Schlaepfer DD: FAK in cancer: Mechanistic findings and clinical applications. Nat Rev Cancer 14: 598-610, 2014.

36. Wu G, Luo J, Rana JS, Laham R, Sellke FW and Li J: Involvement of COX-2 in VEGF-induced angiogenesis via P38 and JNK pathways in vascular endothelial cells. Cardiovasc Res 69: 512-519, 2006

37. Chen XL, Nam JO, Jean C, Lawson C, Walsh CT, Goka E, Lim ST, Tomar A, Tancioni I, Uryu S, et al: VEGF-induced vascular permeability is mediated by FAK. Dev Cell 22: 146-157, 2012.

38. Mariappan MM, Senthil D, Natarajan KS, Choudhury GG and Kasinath BS: Phospholipase Cgamma-Erk Axis in vascular endothelial growth factor-induced eukaryotic initiation factor 4E phosphorylation and protein synthesis in renal epithelial cells. J Biol Chem 280: 28402-28411, 2005.

39. Shojaei F: Anti-angiogenesis therapy in cancer: Current challenges and future perspectives. Cancer Lett 320: 130-137, 2012.

40. Moss A: The angiopoietin:Tie 2 interaction: a potential target for future therapies in human vascular disease. Cytokine Growth Factor Rev 24: 579-592, 2013.

41. Scholz A, Plate KH and Reiss Y: Angiopoietin-2: A multifaceted cytokine that functions in both angiogenesis and inflammation. Ann NY Acad Sci 1347: 45-51,2015.

42. Yuan HT, Khankin EV, Karumanchi SA and Parikh SM: Angiopoietin 2 is a partial agonist/antagonist of Tie2 signaling in the endothelium. Mol Cell Biol 29: 2011-2022, 2009.

43. Cascone $\mathrm{T}$ and Heymach JV: Targeting the angiopoietin/Tie2 pathway: Cutting tumor vessels with a double-edged sword? J Clin Oncol 30: 441-444, 2012.

44. Serbedzija GN, Flynn E and Willett CE: Zebrafish angiogenesis: A new model for drug screening. Angiogenesis 3: 353-359, 1999.

45. Tobia C, Gariano G, De Sena G and Presta M: Zebrafish embryo as a tool to study tumor/endothelial cell cross-talk. Biochim Biophys Acta 1832: 1371-1377, 2013. 